\title{
Case Report of Tumour-induced Osteomalacia with Parotid Gland Tumour as a Focus
}

\author{
Jyotsna Oak, Girish Parmar, Satish Sharma, Bijal Kulkarni, Laxmi Patil \\ Kokilaben Dhirubhai Ambani Hospital, Mumbai, India
}

\begin{abstract}
Tumour-induced osteomalacia (TIO) is a rare paraneoplastic syndrome, which is characterized by overproduction of FGF23 as a phosphaturic agent leading to chronic phosphaturia and hypophosphatemia, associated with inappropriately normal or low levels of vitamin D. We describe a rare case of a 57-year-old Indian female who presented with bone pains, muscle pains and lower limb weakness. On examination she was found to have hypophosphatemia. Our work up led to the identification of a FGF23 secreting parotid tumour. The tumour responsible for symptoms was a pleomorphic adenoma of the parotid gland. Its complete resection resulted in normalisation of patient's symptoms. Laboratory parameters and microsopic examination further revealed a mesenchymal tumour of mixed connective tissue type.
\end{abstract}

Key words: TIO, hypophosphatemia, FGF23

\section{INTRODUCTION}

Hypophosphatemic osteomalacia comprises hereditary and acquired disturbances. Main syndromes described as causing this disease are $\mathrm{x}$-linked hypophosphatemic rickets (XHR), Autosomal Dominant Hypophosphatemic Rickets (ADHR) and Fibrous dysplasia.

TIO is an acquired condition and is related to mesenchymal or mixed connective tissue tumour(s) that markedly expresses FGF23 RNA protein, which cannot be adequately degraded by specific endopeptidases. Other clinical syndromes have been also associated with FGF-23 overproduction, such as NF-1, Mc Cune-Albright Syndrome (MAS). ${ }^{1}$

The FGF-23 protein inhibits type II a and II c sodium phosphate co-transport in proximal convoluted tubules and inhibits renal 1- $\alpha$ hydroxylation of vitamin D.

Although these conditions exhibit different etiopathogenic mechanisms, they share the same pathophysiological pathways i.e., secretion of FGF23 that acts on proximal tubules, and increases renal excretion of phosphate, leading to hyperphosphaturia, and hypophosphatemia with impaired vitamin D metabolism, as FGF23 inhibits 1alpha hydroxylase..$^{2,3}$

The diagnosis is often delayed, as the patient presents with multiple complaints, such as bone and muscle pain and

eISSN 2308-118x

Printed in the Philippines

Copyright (C) 2016 by the JAFES

Received: April 29, 2016. Accepted: July 20, 2016

https://doi.org/10.15605/jafes.031.02.15 muscle weakness. The tumour itself is small and slow growing, and often missed during the clinical examination. As clinical and biochemical changes of TIO are potentially reversible by tumour removal, its localization is essential.

We report a case of chronic hypophosphatemic osteomalacia, characterized by severe muscle weakness, pain and multiple bone fractures. Our aim is to register the case, and also discuss the diagnostic approach and therapeutic management of TIO.

\section{CASE}

A 57-year-old Indian woman, presented with the chief complaints of bilateral leg pains on walking since 15 months, limping to either side since 3 months and currently walking with support of a stick since 1 month. The patient also complained of pain in both upper limbs since 1 month. She had past history of Chikungunya infection 4 years ago and history of left superficial parotidectomy in 2011. Before coming to our OPD, she was treated for Rheumatoid Arthritis, evaluated for multiple myeloma and connective tissue disorder due to intense pain in lower limbs. She had received oral calcitriol before coming to hospital. However, the patient was not given phosphorous supplement. There was no family history of metabolic bone disease. There was no history of loss of weight, decreased appetite, and swelling or mass anywhere in the body except a left parotid enlargement. 
On physical examination, the patient had antalgic gait, and left parotid enlargement $3 \times 4 \mathrm{~cm}$. She had localized tenderness over multiple ribs and multiple tender points over the lower limbs. She had left sided lower motor neuron facial palsy. Motor strength in the lower limbs was grade 5 , but she had intense pain (numerical response scale 8/10) in both the feet and right hip.

Initial laboratory testing revealed a calcium $9.6 \mathrm{mg} / \mathrm{dl}(8.8-$ $10.2 \mathrm{mg} / \mathrm{dl}$ ), phosphorus level $2 \mathrm{mg} / \mathrm{dl}$, alkaline phosphatase was marginally elevated $179 \mathrm{U} / \mathrm{L}$, creatinine 0.6 mg/dl, SGOT 22.1(U/L) SGPT 23.8(U/L) PTH 5.6 pg/ml, and vitamin D $17.5 \mathrm{ng} / \mathrm{ml}$. Complete blood count, liver function tests, renal function tests, TSH, serum protein electrophoresis and CPK were normal (Table 1). We were unable to measure 1,25 vitamin D as the test was not available. The patient's ANA and Rheumatoid factor was negative. Her EMG and Nerve conduction studies were normal.

\begin{tabular}{|c|c|c|}
\hline & Patient value & Normal value \\
\hline Calcium & $9.6 \mathrm{mg} / \mathrm{dl}$ & $8.8-10.2 \mathrm{mg} / \mathrm{dl}$ \\
\hline Phosphorous & $2 \mathrm{mg} / \mathrm{dl}$ & $2.7-4.5 \mathrm{mg} / \mathrm{dl}$ \\
\hline Creatinine & $0.6 \mathrm{mg} / \mathrm{dl}$ & $.67-1.17 \mathrm{mg} / \mathrm{dl}$ \\
\hline SGOT & $22.1 \mathrm{U} / \mathrm{L}$ & $10-50 \mathrm{U} / \mathrm{L}$ \\
\hline SGPT & $23.8 \mathrm{U} / \mathrm{L}$ & $0-41 \mathrm{U} / \mathrm{L}$ \\
\hline PTH & $5.6 \mathrm{pg} / \mathrm{ml}$ & $15-65 \mathrm{pg} / \mathrm{ml}$ \\
\hline VIT D & $17 \mathrm{ng} / \mathrm{ml}$ & $>30 \mathrm{ng} / \mathrm{ml}-<100 \mathrm{ng} / \mathrm{ml}$ \\
\hline
\end{tabular}

Radiological studies showed bilateral tibial shaft fractures, multiple fractures in bilateral tarsals (Figures 1 to 3). A PET Scan showed multiple insufficiency fractures of bilateral tibia, neck of right femur, metacarpal bones and scapula (Figures 4 to 7 ).

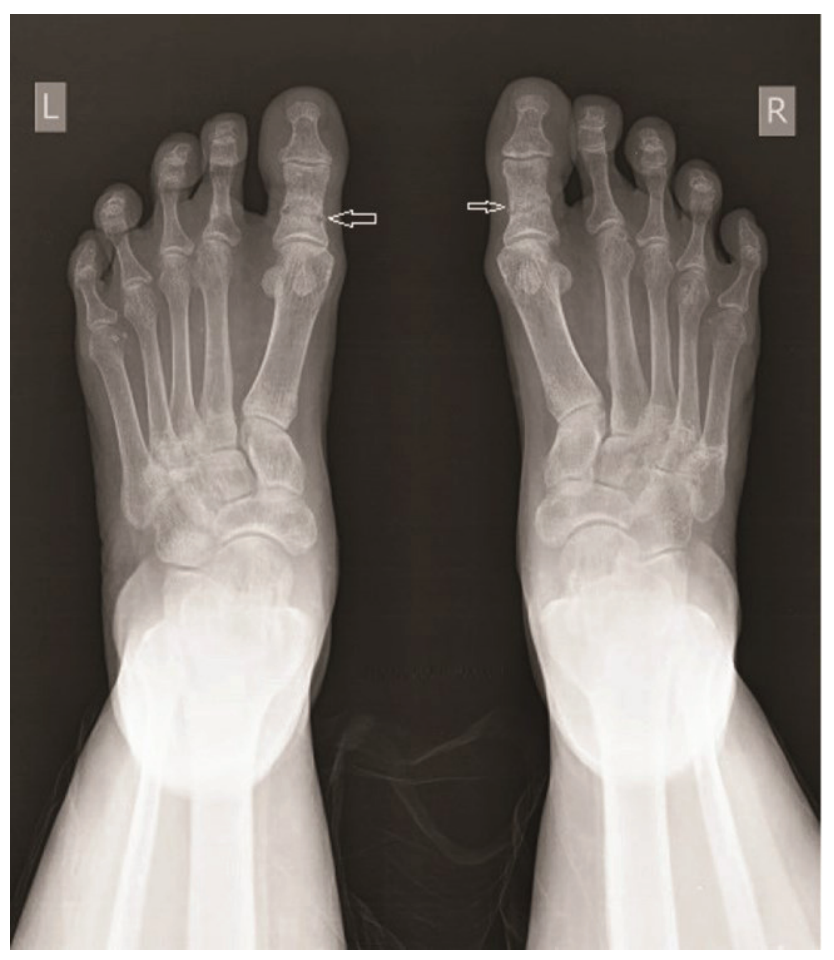

Figure 1. X-Ray showing metatarsal fracture.

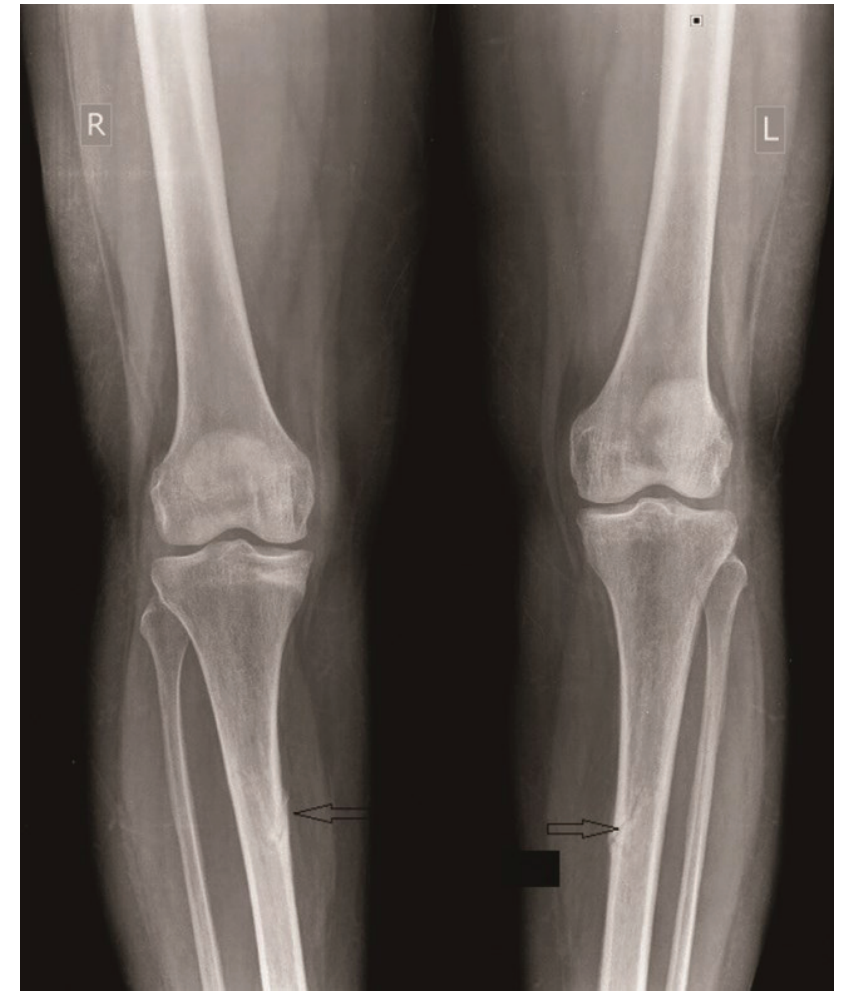

Figure 2. X-ray showing bilateral mid-shaft tibia fracture.

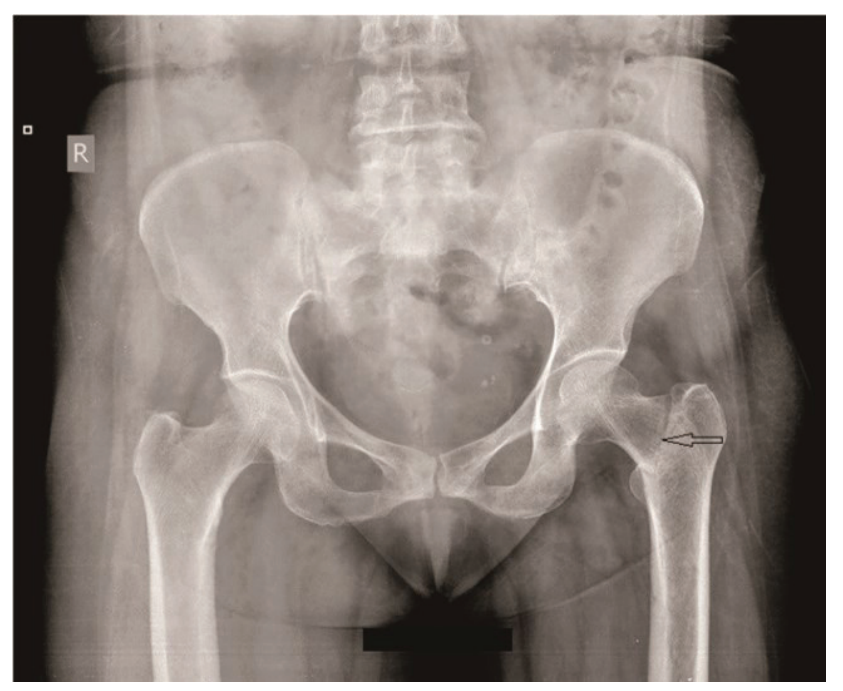

Figure 3. X- ray showing neck femur fracture on left side.

Instead of 24-hour urinary phosphorous, levels of phosphorus and creatinine were measured from a spot urine sample and tubular re-absorption of phosphorus (TRP) was calculated. Walton and Bijovet Nomogram was then used to estimate the TMP/GFR, which was 1.6, suggestive of renal phosphate wasting. The patient's FGF23 was $500 \mathrm{RU} / \mathrm{ml}$.

Since the parotid tumour also has a mesenchymal component, it was thought to be a source producing FGF23. ${ }^{68} \mathrm{Ga}$-DOTATE scan was done which showed increased uptake over left parotid, SUV (Standard uptake values) max - 97.5, other areas, had normal physiological uptake (Figure 8). 


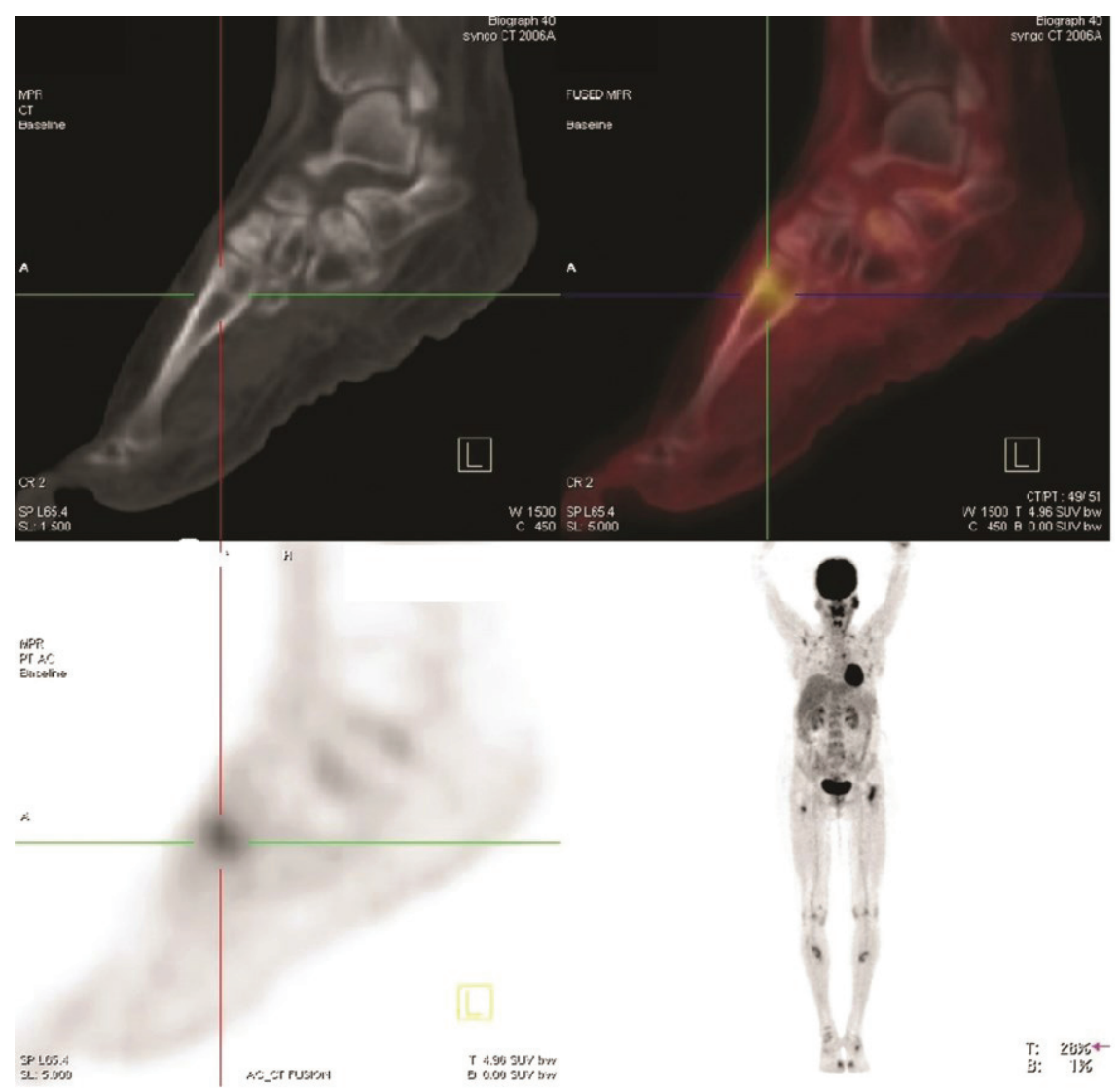

Figure 4. PET scan picture showing uptake over fracture part.

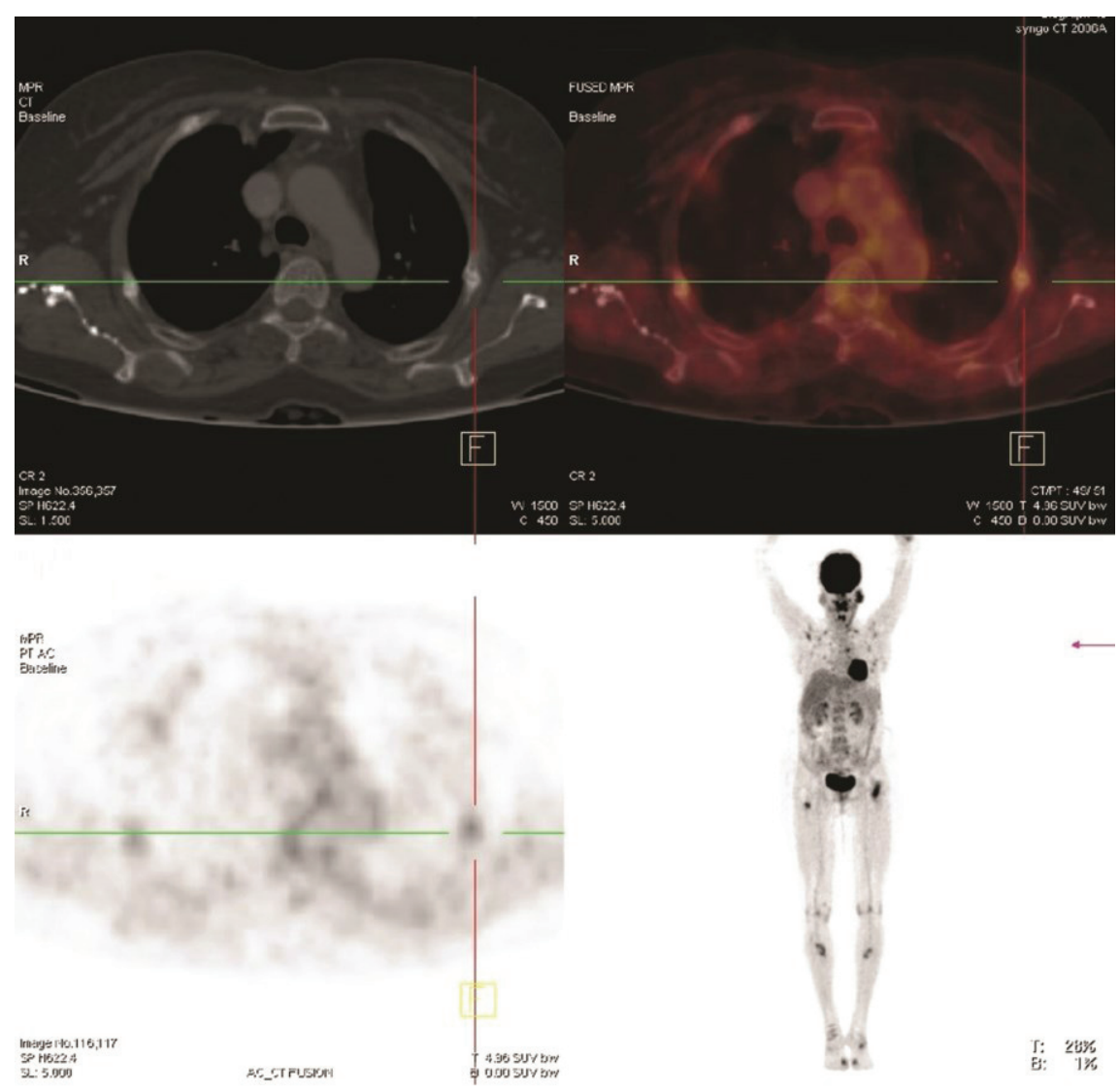

Figure 5. PET scan showing fracture of ribs. 


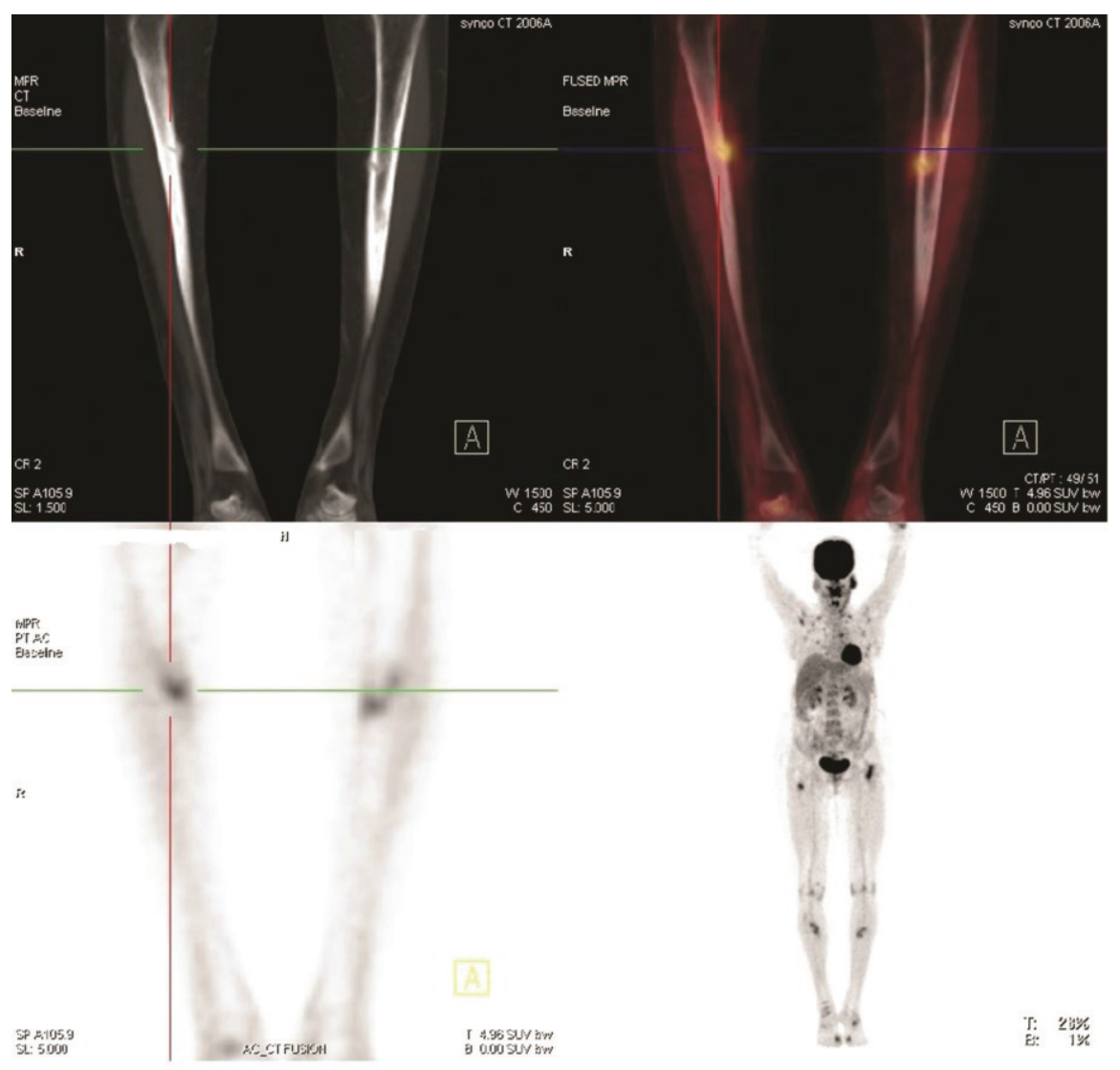

Figure 6. PET scan showing fracture of tibial shaft.

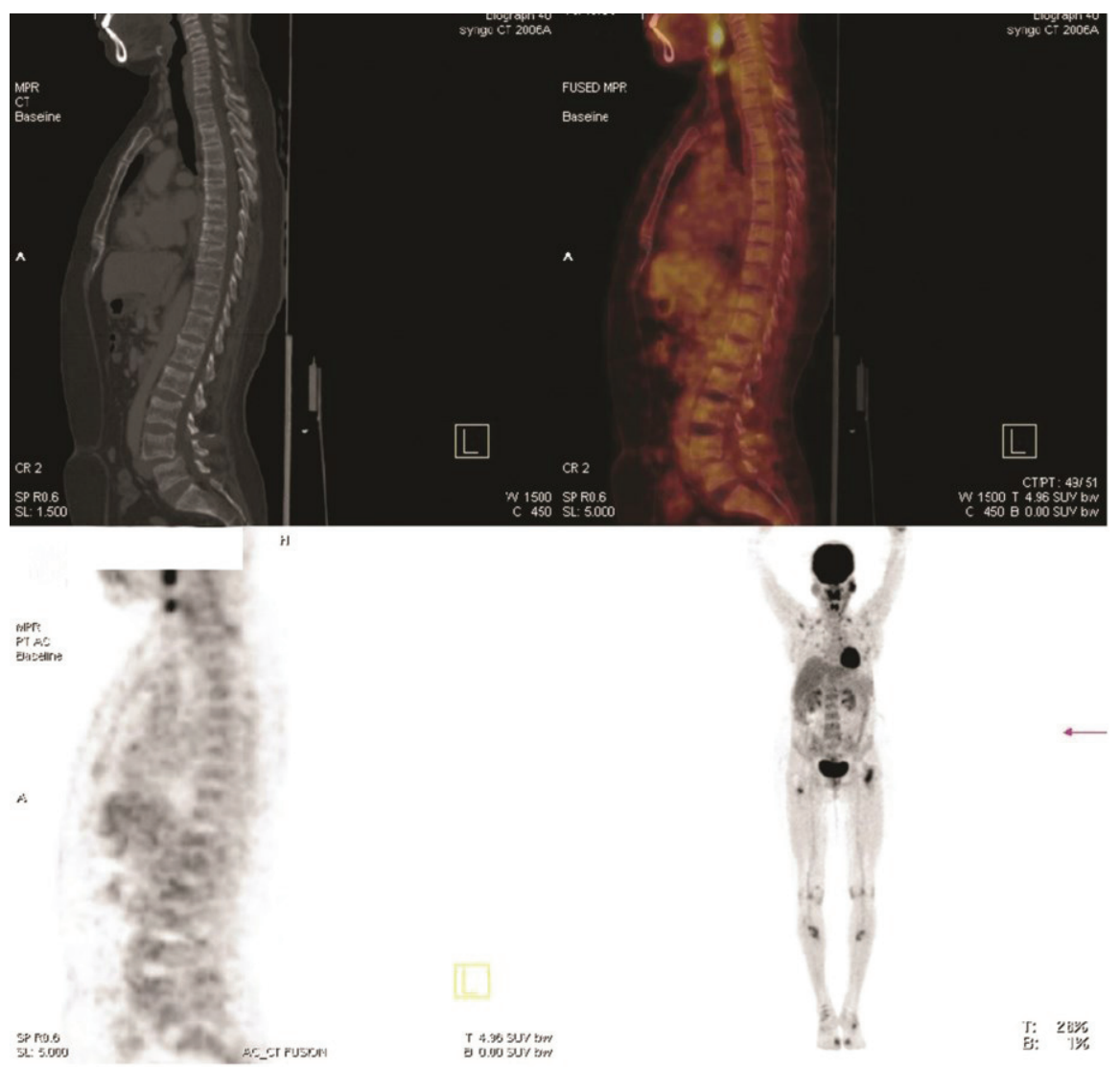

Figure 7. PET scan showing multiple fractures. 


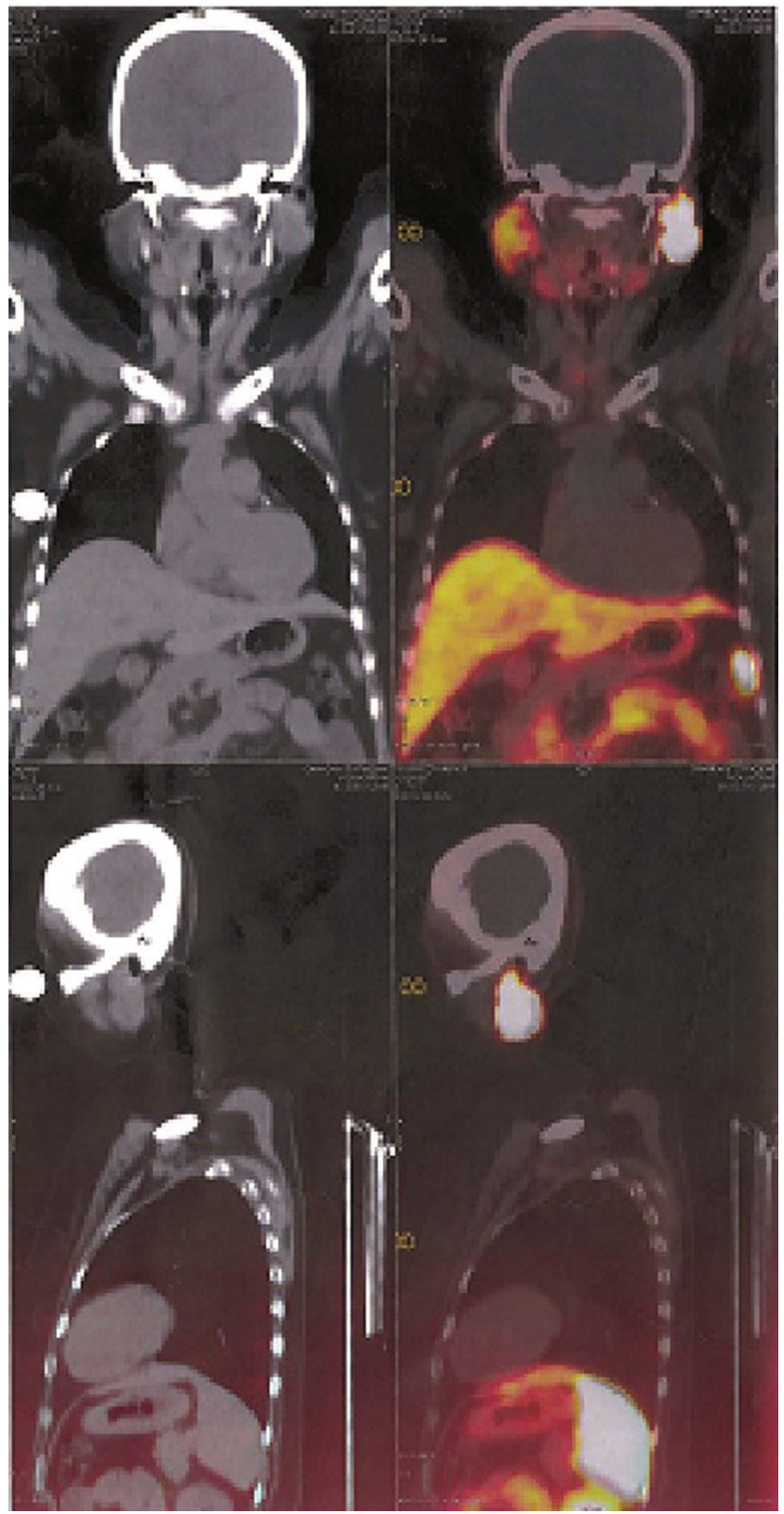

Figure 8. ${ }^{68}$ Ga-DOTATE scan showing coronal and saggital view of mass in left parotid.

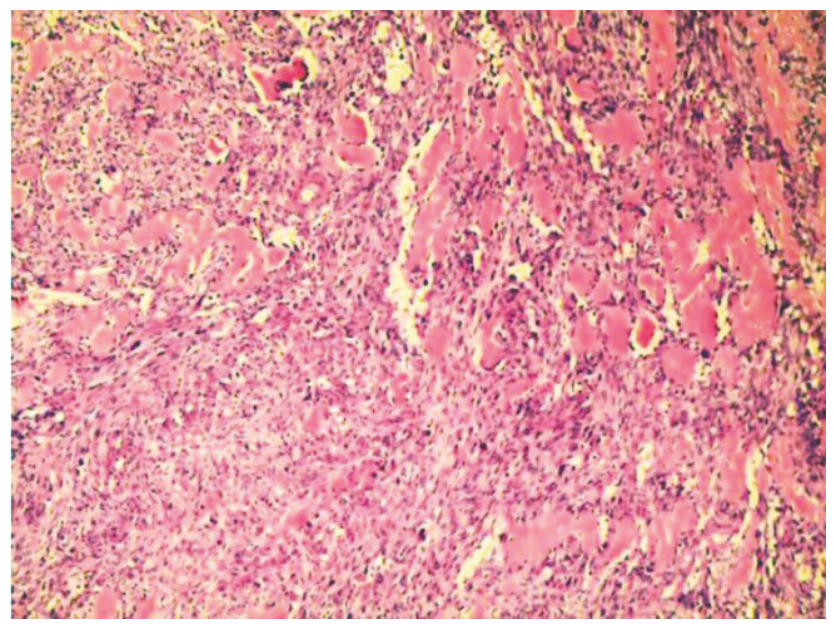

Figure 9. Cellular spindle cell tumour with deposition of basement membrane like eosinophilic material (20x).

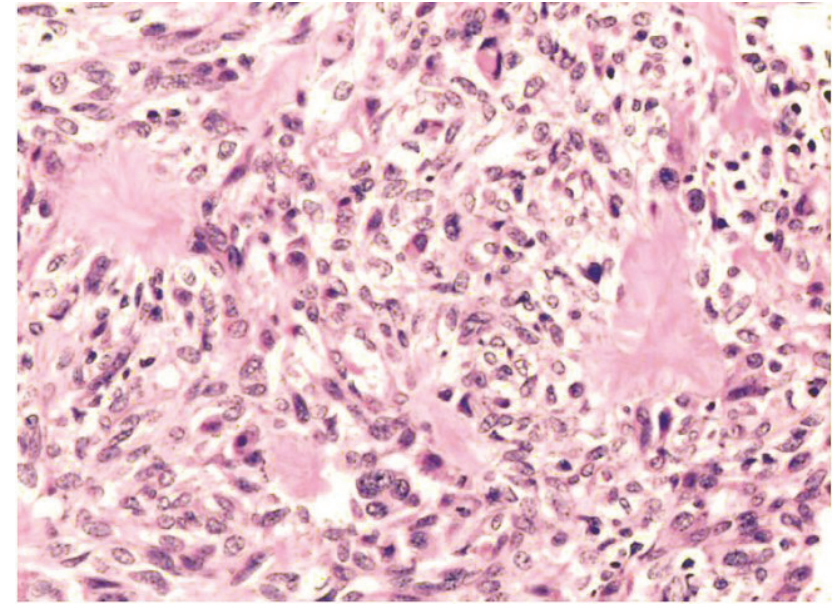

Figure 10. High power view of the tumour showing increased cellularity and mild nuclear pleomorphism. However the mitotic activity is low (40x).

The patient was started on oral phosphate supplement 2-3 gms/ day, and her symptoms improved from baseline, but serum phosphorous remained on lower side. The patient underwent left parotid resection. The excised left parotid gland measured $4 \times 3 \times 2.5 \mathrm{~cm}$ and on cut section there was a grayish white ill-defined firm and focally hard solid tumour measuring $2.8 \times 2.2 \times 2 \mathrm{~cm}$. A similar nodule measuring $0.5 \mathrm{~cm}$ in diameter was found in the adjacent parotid parenchyma. The rest of the parotid was unremarkable. The histopathology showed cellular myoepithelial rich pleomorphic adenoma of the parotid gland. Focal nucleal pleomorphism was noted. Mitotic count was low (Figures 9 and 10). Immunostaining of the tumour tissue for FGF23 could not be done as this test was not available.

The patient's symptoms improved after resection, and serum phosphorous done 1 week after resection showed a normal phosphorus.

\section{DISCUSSION}

Tumour induced osteomalacia (TIO) is an acquired disorder of renal phosphorus wasting. It is associated with tumour producing phosphaturic factor leading to phosphaturia, low serum phosphorus levels and low or inappropriately normal serum calcitriol levels. Hypophosphatemia is normally a stimulus for production of calcitriol, and the level of normal vitamin D is abnormal in the context of low serum phosphorus level. ${ }^{4,5,6}$

Clinical symptoms include the gradual onset of muscle weakness, fatigue and bone pain especially from ankle, legs, hips and back. ${ }^{3-5}$ Insufficiency fractures and proximal muscle weakness causes pain and inability to walk; so the patient becomes slowly bed bound. Our patient had multiple fractures of tibia, femur and metatarsals due to which she had gradually become bed bound. She was diagnosed and treated as having Rheumatoid Arthritis due to the intense pain in her legs while walking. 
The phosphaturic peptides are known as phosphatonins and FGF23 is the most extensively described. FGF23 has an important role in maintaining phosphorus homeostasis. ${ }^{3,-6}$ In TIO, the level of FGF23 is high and results in phosphate wasting through the urine. ${ }^{7}$ If the responsible tumour is surgically removed, the abnormalities of phosphorus wasting and vitamin D metabolism are rapidly corrected. According to White, $\mathrm{PTH}$ which decreases renal phosphorus reabsorption is usually within normal range in TIO patients. ${ }^{8}$ Hence in our patient, due to increased FGF23, the serum PTH must have been low. Other studies have supported this hypothesis by showing that implantation of tumour tissue into nude mice resulted in increased urinary phosphorus excretion. ${ }^{9}$

When TIO tumours and several control tissue were tested by northern blot for the presence of FGF23 transcripts, it was determined that FGF23 was present in a tumour lysate and it was confirmed by western blot analysis, with an anti human FGF antibody. The mice receiving implanted transcripts from tumour also showed growth retardation, kyphosis, osteomalacia and marked decrease in renal $1 \alpha$ hydroxylase. Under normal circumstances, FGF23 has an important role in maintaining phosphorus homeostasis . In patients of TIO however, circulating level of FGF23 are high which leads to renal phosphate wasting. ${ }^{2}$

FGF23 also has a central role in the pathogenesis of autosomal dominant hypophosphatemic rickets (ADHR) which is caused by mutation in the FGF23 gene that makes peptides resistant to degradation by regulatory proteases. Some patients of TIO have normal FGF23 level. This lead to the discovery of other phosphatonins including secreted frizzled related protein 4 (SFRP-4). Matrix extracellular phosphoglycoprotein (MEPE) and fibroblast growth factor (FGF7) whose roles in TIO are under investigations. ${ }^{6,11}$

TIO is a rare condition. Our case demonstrated the importance of considering the diagnosis of $\mathrm{TIO}$ and assessing serum phosphorus levels in patients with unusual osteomalacia and persistent musculoskeletal symptoms. Measurement of serum phosphorus is an important step for understanding phosphaturia. ${ }^{11}$ Also with the levels of serum calcium, alkaline phosphate, PTH, 25(OH) D3, 1,25 dihydroxyvitamin D should be measured to distinguish other causes of hypophosphatemia and osteomalacia.

A spot 2 hour urine sample was collected in our patient. Calculation of TMP/ GFR and a nomogram was used to derive this from serum phosphorus and tubular reabsorption of phosphate (TRP $=1$ - [urine phosphorus] $\mathrm{x}$ [serum creatinine]/[urine creatinine] x [serum phosphorus level] $)^{11}$. This is a reliable tool for evaluation of hypophosphatemia. The patient was not on any phosphorous supplement at that time. In our patient, TMP/GFR was low despite hypophosphatemia which indicated renal phosphorus wasting. ${ }^{11}$

FGF23 is a confirmatory test for diagnosis of TIO. In one survey, 22 patients with clinical evidence of TIO had elevated FGF23.11 These tumours usually arise from soft tissue and bones and are benign in nature. The definitive treatment of TIO being resection of a tumour, localization of such tumour is essential. ${ }^{11}$

In our patient, the source of the tumour was readily visible. But tumours can occur in elusive sites and their localisation can be challenging. Careful physical examination with special attention to oral cavity and extremities is needed.

For tumour localisation, imaging modalities such as $\mathrm{X}$ ray, CT and MRI can be used. Some tumours express surface somatostatin receptors. Somatostatin receptor PET scan is used as a diagnostic tool in refractory cases. In our patient Somatostatin receptor PET scan was used as nuclear imaging method. Radiolabelled octreotide was injected in a patient and whole body follow images were taken. Tumours that have surface somatostatin receptors bind to the octreotide and light up images.

Renal phosphate wasting and abnormal vitamin D metabolism can also be seen in X-linked hyphosphatemia (XLH) and ADHR (Autosomal dominant hypophosphatemic rickets) and both are caused by genetic mutations. As indicated by their names, they differ in mode of inheritance. These disorders present in childhood, although ADHR can exhibit variable and delayed onset. In all these syndromes circulating phosphatonins lead to inhibition of renal tubular phosphate reabsorption and downregulation of renal $1 \alpha$ hydroxylase. ${ }^{1,11}$

TIO is managed by complete resection of the tumour which results in decrease in bone pain and muscle pain and healing of multiple fractures within several months. ${ }^{11}$ Until the tumour is located and resected, the patient requires 1-4 gm of phosphorus/day in divided dosage as well as calcitriol supplementation (1-3 gm/day). ${ }^{11}$ These lead to renal and gastrointestinal phosphorus reabsorption and prevent secondary hyperparathyroidism. ${ }^{11}$ The patient had already received calcitriol as well as alphacalcidol before coming to hospital and had no symptomatic relief and her serum vitamin D level was normal, hence calcitriol or alphacalcidol was not started. Our patient was given oral phosphorus (4.5 gm/day), until she underwent resection of the tumour. Subsequent to the resection, her serum phosphorous values improved. She was given phosphorous supplementation, which was tapered gradually. Over the next few months, bone and muscle pain subsided and she was able to walk without support. 


\section{CONCLUSION}

TIO is an acquired disorder of renal phosphate wasting that is associated with tumour. Patients with TIO present with hypophosphataemia with inappropriately suppressed 1,25 $(\mathrm{OH}) 2$ D concentration. Clinical symptoms include gradual onset of muscle weakness, fatigue and bone pain, especially for ankles, legs, hips and back. Insufficiency fractures are common and proximal muscles weakness can become severe enough for patients to require wheel chair or they become bedbound. This case highlights the importance of measuring serum phosphorus and phosphate clearance in patients with unusual musculo-skeletal pain and myopathic weakness. ${ }^{68} \mathrm{Ga}$-DOTATE scan helps in localization of such a tumour and surgical resection can lead to total cure.

\section{Ethical Consideration}

Patient consent form has been procured prior to the case report study.

\section{Statement of Authorship}

All authors have given approval to the final version submitted.

\section{Author Disclosure}

All the authors have declared no conflict of interest to the work carried out in this paper.

\section{Funding Source}

None.

\section{References}

1. Bringhurst F, Demay MB, Krane SM, Kronenberg HM. Disorders of bone and mineral metabolism. In: Harrison's Principles of Internal Medicine, $19^{\text {th }}$ ed. New York: McGraw Hill; 2012.

2. Larsson T, Marsell R, Schipani E, et al. Transgenic mice expressing fibroblast growth factor 23 under the control of $\alpha 1$ (I) collagen promoter exhibit growth retardation, osteomalacia, and disturbed phosphate homeostasis. Endocrinology. 2004;145(7):3087-94. https:// doi.org/10.1210/en.2003-1768\#sthash.PL1RQgCp.dpuf.

3. Shimada T, Hasegawa H, Yamazaki Y, et al. FGF-23 is a potent regulator of vitamin $\mathrm{D}$ metabolism and phosphate homeostasis. J Bone Miner Res. 2004;19(3):429-35. https://doi.org/10.1359/JBMR. 0301264.

4. Kumar R. Tumor-induced osteomalacia and the regulation of phosphate homeostasis. Bone. 2000;27(3):333-8. https://doi.org/10. 1016/S8756-3282(00)00334-3.

5. Jan de Beur SM. Tumor-induced osteomalacia. JAMA. 2005;294(10):1260-7. https://doi.org/10.1001/jama.294.10.1260.

6. Berndt TJ, Schiavi S, Kumar R. "Phosphatonins" and the regulation of phosphorous homeostasis. Am J Physiol Renal Physiol. 2005;289(6): F1170-82. https://doi.org/10.1152/ajprenal.00072.2005.

7. Shimada T, Mizutani S, Muto T, Yoneya T, Hino R, Takeda S, et al. Cloning and characterization of FGF23 as a causative factor of tumor induced osteomalacia. Proc Nati Acad Sci USA. 2001; 98(11):6500-5. https://doi.org/ 10.1073/pnas.101545198.

8. White KE, Bringhurst R, Econs MJ. Genetic disorders of phosphate homeostasis. In: J Larry Jameson, Leslie De Groot DM De Kretser. Endocrinology: Adult and Pediatric. Philadelphia: Elsevier/Saunders; 2010.

9. Chalew SA, Lovchik JC, Brown CM, Sun CCJ. Hypophosphatemia induced in mice by transplantation of a tumor-derived cell line from a patient with oncogenic rickets. J Paediatr Endocrinol Metab. 1996;9(6):593-7. https://doi.org/10.1515/JPEM.1996.9.6.593.

10. Folpe AL, Fanburg-Smith JC, Billings SD, Bisceglia M, Bertoni F, Cho JY, et al. Most osteomalacia-associated mesenchymal tumors are a single histopathologic entity: An analysis of 32 cases and a comprehensive review of literature. Am J Surg Pathol. 2004;28(1):1-30. PMID: 14707860.

11. Halperin F, Anderson RJ, Mulder JE. Tumor-induced osteomalacia: The importance of measuring serum phosphorus levels. Nat Clin Pract Endocrinol Metab. 2007;3(10):721-5. https://doi.org/10.1038/ ncpendmet0639.

Authors are required to accomplish, sign and submit scanned copies of the JAFES Author Form consisting of: (1) the Authorship Certification that the manuscript has been read and approved by all authors, and that the requirements for authorship have been met by each author, (2) the Author Declaration that the article represents original material that is not being considered for publication or has not been published or accepted for publication elsewhere, (3) the Statement of Copyright Transfer[accepted manuscripts become the permanent property of the JAFES and are licensed with an Attribution-Share Alike-Non-Commercial Creative Commons License. Articles may be shared and adapted for non-commercial purposes as long as they are properly cited], (4) the Statement of Disclosure that there are no financial or other relationships that might lead to a conflict of interest. For Original Articles involving human participants, authors are required to submit a scanned copy of the Ethics Review Approval of their research. For manuscripts reporting data from studies involving animals, authors are required to submit a scanned copy of the Institutional Animal Care and Use Committee approval. For Case Reports or Series, and Images in Endocrinology, consent forms are required for the publication of information about patients. Articles and any other material published in the JAFES represent the work of the author(s) and should not be construed to reflect the opinions of the Editors or the Publisher.

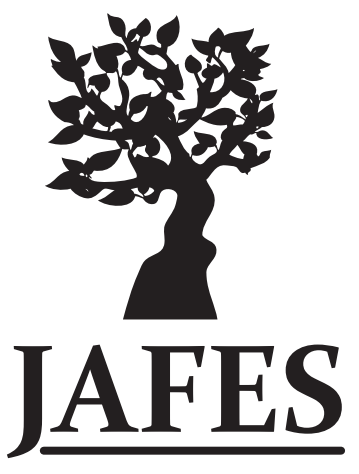

\section{Send your paper to the publication pathway. Instructions to Authors at www.ASEAN-endocrinejournal.org.}

